\title{
Los Cachorros: fragmento de una exploración total
}

Después de terminar $L a$ casc verde y mientras se tomaba un respiro antes de empezar su tercera novela, Vargas Llosa se decidió a escribir una historia que lo venía rondando desde hacía tiempo: otra vez sobre viejos recuerdos limeños, otra vez con esa indiscernible mezcla de realidad e imaginación, otra vez sobre colegiales de clase media. La historia se convirtió en un cuento largo (o novela corta, si se atiende, más que a sus proporciones, a su tensión estructural) que iba a titularse Picbula Cuéllar, título brutal y provocador para el lector peruano (la palabra pichula, que designa el sexo masculino, es impronunciable $y$, por cierto, impublicable), pero que finalmente se llamó, con mayor cordialidad, Los cachorros (Picbula Cuéllar pasó a ser un discreto subtítulo en la edición original de 1967). Aunque, como el mismo autor lo admite, el libro es un trabajo de menor calado situado en medio de las eminencias máximas de sus novelas, no es, de ningún modo, un fruto que pueda considerarse literariamente secundario o residual. Y esto no sólo porqué la historia que nos cuenta tiene una notable identidad -es, a la vez, parte y unidad que se suma al mundo novelístico de Vargas Llosa- o porque al trazar la inhibida y trivial psicología del protagonista, el autor endiabladamente haya redondeado una perspicaz caricatura de la adolescencia en crisis, sino, sobre todo, porque Los cacborros es una nueva coronación de su maestría técnica, una etapa de experimentación formal que lleva a otros extremos los procedimientos narrativos con los que antes ya nos había pasmado.

Por atmósfera y temática, Los cacborros está muy cerca de Los jefes y La ciudad $y$ los perros; ${ }^{1}$ pero, estilísticamente, es un libro que deriva de La casa verde, que quizá no habría podido ser escrito antes de esta

\footnotetext{
- Véase Carlos Martínez Morenc, "Una hermosa ampliación". Amaru, núm. 3. p. 84; y Carlos Barral, "Introducción" en Los cacbovos, Barcelona, Lumen, 1967 , pp. 8.9 .
} 
novela. Con La casa verde Vargas Llosa se acercó a esa novela plenaria que constituye, para él, la forma suprema de representación literaria de la vida misma. Con Los cachorros realiza, a su modo y en otra escala, un nuevo intento de totalizar un microcosmos --el de los adolescentes miraflorinos, el mundo de Alberto en La ciudad y los perros-y proponer esa instantánea multidimensional como una metáfora, como una alegoría, como una visión tragicómica de la sociedad peruana. Como suele suceder con el autor, los datos que el relato hurta a la realidad son los más increíbles, los más pavorosos: nada menos que un muchacho emasculado por un perro. Se trata de un hecho que ocurrió en algún lugar del Perú y que Vargas Llosa leyó, en un recorte periodístico, años atrás. El asunto era terrible pero desde el punto de vista literario parecía casi inservible; o mejor, era un asunto que ya había sido utilizado por Hemingway en The Sun Also Rises. Poco a poco, el tema fue convirtiéndose en una obsesión para el autor y hallando su forma propia. Reinventando sobre esa escueta base un protagonista víctima y poniéndolo en el centro de su historia, Vargas Llosa lo rodeó de personajes, recuerdos y anécdotas emanados de un ambiente o época que sigue alimentando -como una visión fija, que se resiste a desaparecer- su febril imaginación y su energía creadora: la vida de colegio, la etapa que es a la vez su melancólico tiempo perdido y su edad de la razón. Vargas Llosa vuelve sobre sus pasos y encuentra a sus héroes: los jovencitos de la pequeña burguesía limeña que estudian en el Colegio Champagnat de Miraflores.

Se trata de un colegio similar al de La Salle, donde hizo sus estudios el autor $y$ que quedaba en una zona relativamente humilde de Lima. E1 vivió, en cambio, en Miraflores, cerca del Champagnat, colegio que centra este relato. $\mathrm{Ha}$ fundido, pues, recuerdos de lo vivido en $\mathrm{La}$ Salle, escenas vistas en los alrededores del Champagnat y la anécdota leída en un diario. En sus correrías de pandilla por las calles y los cines de barrio, los antros del billar $\mathrm{y}$ del fulbito, las fiestas juveniles $\mathrm{y}$ los jactanciosos flirteos, estos muchachos rinden culto al machismo y a la violencia gratuita, se inventan un código de vida que colma provisionalmente los vacíos de su inadaptación social. Para superar el muro cerrado de la formación familiar y la educación tradicional (que tienen una idea bastante cándida de ellos), adoptan máscaras terribles, rivalizan con el mundo adulto; mintiéndose para llegar a ser lo que quieren, acaban por ser una jauría de tramposos, los usurpadores de los grandes papeles, los frenéticos impostores que conocimos en La ciudad y los perros. La profunda identificación de los personajes de Vargas Llosa con las formas 
de violencia y brutalidad física, se advierte hasta en la fiera jerarquía (zoológica, frecuentemente) a la que son sometidos sus propios nombres: "jefes", "esclavos", "perros", el Jaguar, Boa, la Selvática, los Inconquistables. Ahora se agregan a la lista estos "cachorros", estos niñosbien disfrazados de coléricos a los que afanosamente busca integrarse el personaje signado con el apodo más procaz: Pichula Cuéllar. Cuéllar intenta lo que no intentó el Esclavo: la mimética fusión con el círculo de "jefes" (Choto, Chingolo, Mañuco, Lalo), de los que mandan e imponen su prestigio, sin tener la capacidad que esa adaptación requiere. Ello explica que su historia tenga un sabor entre ridículo y tristón, que parezca un penoso malentendido.

Hay algo terrible pero también cómico en los "cachorros" miraflorinos; algo que los exalta y los frustra. El caso de Cuéllar es todavía más agudo $\mathrm{y}$, dentro de los pactos del clan, irremediable. El obstáculo que le impide participar en los ritos del machismo es físico: ha sufrido una castración, ha sido herido en el centro de su virilidad. Alrededor de ese hecho, el relato se organiza como una exposición casi didáctica de la rápida ascensión y la lenta caída del héroe. En un ritmo acelerado se muestran los hechos claves que constituyen la vida de los "cachorros", desde el fin de la infancia hasta su entrada a la madurez (de los 8 años a los treinta $y$ tantos, aproximadamente). El proceso se divide en seis partes:

I: Incorporación exitosa al grupo y castración de Cuéllar.

II: Nacimiento del apodo y alegre fama del protagonista.

III: Primera crisis: desadaptación, timidez y fracaso de sus tácticas de defensa.

IV: Crisis definitiva: enamoramiento e imposible declaración a Teresita.

V: Profunda inestabilidad interior y machismo exhibicionista.

VI: Infantilismo, separación del grupo y muerte del protagonista.

Desde su ingreso al colegio, Cuéllar se gana la admiración general de sus compañeros: es estudioso pero también hábil futbolista. Está dotado no sólo para sobrevivir a las presiones del grupo, sino para imponerse a él. Es importante anotar que ni siquiera su emasculación lo exilia inicialmente del aprecio colectivo; al contrario, es un motivo más para que le demuestren su solidaridad y hasta se venguen absurdamente del perro que lo castró: "Ellos lo estábamos vengando, Cuéllar, en cada 
recreo pedrada y pedrada contra la jaula y él bien hecho, prontito no le quedaría un hueso sano al desgraciado" (p. 25). El accidente, en sí mismo trágico, le abre a Cuéllar las puertas de una vida totalmente distinta del grupo, quizá menos vistosa, quizá más auténtica. La disminución física, que debería alejarlo de las efímeras glorias deportivas, lo aferra más a ellas; el frenesí muscular lo enajena: "cosa rara, en vez de haber escarmentado con el fútbol (¿no era por el fútbol, en cierta forma, que lo mordió Judas?) vino más deportista que nunca. En cambio, los estudios comenzaron a importarle menos" (p. 31). Ocurre que Cuéllar no quiere renunciar a la impostura colectiva y que "ser uno más del grupo" es, para él, un esfuerzo casi profesional de su persona: para cultivar el machismo el castrado Cuéllar tiene que asumir una ficción de segundo grado (fingir que no es realmente un castrado, fingir que puede fingir la hombría de los demás). Gregario, débil de carácter, bufón de su propio drama, Cuéllar convierte la desgracia sufrida en una chirle fuente de privilegios: sus padres lo miman como a una niña frágil, los profesores son indulgentes con él, los amigos francamente lo envidian. La castración cobra, a los ojos de los demás, un carácter positivo y hasta (lo que parece un helado sarcasmo) deseable: "Desde el accidente te soba, le deciamos, no sabías nada de quebrados y, qué tal raza, te pusicron dieciséis... Quién como tú, decía Choto, te das la gran vida, lástima que Judas no nos mordiera también a nosotros..." (p. 31). La vida del protagonista empieza entonces a deslizarse como una historieta mediocre y grotesca, cuya persistente falsedad impide a Cuéllar reconocerse en Cuéllar: la labor de Judas es completada por los amigos, por el medio social en el que desarrolla su personalidad. La castración física llega a importar menos, dentro de los términos del relato, que la castración sistemática y la alienación progresiva a que lo somete el grupo; son "las dentelladas del prójimo":2 las que verdaderamente lo destruyen. Es importante que el personaje nunca aparezca solo: es una especie de emanación de su pandilla, el indefenso objeto de sus miradas. Carece prácticamente de vida propia: ignora la reflexión, ignora el autorreconocimiento. Aunque parezca increíble, acepta con simpatía el apodo creado para humillarlo, para liquidarlo socialmente. En una horrible inversión del código del machismo, el protagonista se infiere a si mismo la ofensa como un elogio: "y en Primero de Media se había acostumbrado tanto que, más bien, cuando le decían Cuéllar se ponía serio y miraba con des-

2 Mario Benedetti, Letras del continente mestizo (Montevideo, Ediciones Arca, 1967), p. 199. 
confianza, como dudando ¿no sería burla? Hasta estiraba la mano a los nuevos amigos diciendo mucho gusto, Pichula Cuéllar a tus órdenes": (p. 39).

Con la turbulenta llegada de la adolescencia, la ficción de Cuéllar empieza a mostrar sus primeras grietas: mientras los compañeros pasan del deporte y del puro vagabundeo, a las enamoradas y a las fiestas de cumpleaños, mientras la edad va reclamando nuevos intereses humanos, Cuéllar se estanca emocionalmente y no participa en el trato social con las chicas. No consigue tener enamorada, tal vez porque eso supone un enfrentamiento estrictamente personal, donde el prestigio de la patota ya no cuenta. Su incipiente erotismo se manifiesta en actos de voyeurismo ("lo veíamos en la oscuridad de la platea, sentadito en las filas de atrás, encendiendo pucho tras pucho, espiando a la disimulada a las parejas que tiraban plan', (p. 54), y, más frecuentemente, en ridículos gestos de matonería y desprecio por las normas (se pelea con Lalo porque éste tiene enamorada, se emborracha y se porta mal en las fiestas; hace competencias de velocidad con el auto, etc.). Como un nuevo signo de disminución y desventaja frente al resto, Cuéllar empieza a tartamudear, a traicionarse bajo su máscara. El grupo lo somete a una nueva y última prueba: la declaración a Teresita Arrarte, la muchacha de la cual Cuéllar se enamora sinceramente. No logra vencer el desafío y, pese a que busca nuevos disfraces para disimular su impotencia psicológica (recobra su sociabilidad, afirma que una operación le devolverá la normalidad, manifiesta vagos intereses "intelectuales" por la política, la religión, el espiritismo, la vida profesional)," el fracaso se hace evidente cuando Cachito Arnilla lo reemplaza en el amor de Teresita. El descrédito de Cuéllar es general y las sanciones implacables: "Pero las chicas ahora lo defendian [a Cachito]: bien hecho, de quién iba a ser la culpa sino de él [de Cuéllar], y Chabuca ¿hasta cuándo iba a esperar la pobre Tere que se decidiera?, y la China qué iba a ser una perrada, al contrario, la perrada se la hizo él, la tuvo perdiendo su tiempo tanto tiempo y Pusy además Cachito es muy bueno, Fina y simpático y pintón y Chabuca y Cuéllar un tímido y la China un maricón" (p. 84).

Así, el protagonista se precipita en el vértigo del infantilismo: mientras la antigua pandilla empieza a desbandarse con los noviazgos, la uni-

${ }^{3}$ Característicamente, sus inclinaciones políticas son reaccionarias ("Hitler no fue tan loco como contaban, en unos añitos hizo de Alemania un país que se le emparó a todo el mundo", p. 74) y sus ideales profesionales, arribistas ("seguiría abogacía... pero no para ser picapleitos sino para entrar a Torre Tagle [la Cancillería peruana] y ser diplomático", p. 75). 
versidad y la vida adulta, Cuéllar vive a destiempo, a la caza de emociones ya superadas. A las habladurías de la gente, él responde con una inoperante involución a las etapas clásicas del machismo: frecuenta burdeles y bares, se exhibe por despecho (como Miguel en "Día domingo" de Los jefes) corriendo olas en un mar embravecido, se junta con muchachitos: "Su carro andaba siempre repleto de rocanroleros de trece, catorce, quince años $\mathrm{y}$, los domingos, se aparecia en el Waikiki (házme socio, papá, la tabla hawaiana era el mejor deporte para no engordar y él también podría ir, cuando hiciera sol, a almorzar, con la vieja, junto al mar) con pandillas de criaturas, mirenlo, mírenlo, ahí está... (p. 98). El desmedido e inútil afán de figuración lo va dejando solo - "resulta cada vez más difícil juntarse con él" (p. 98), comenta la voz anónima del grupo- hasta un punto en que ya no tiene salida. Un día, oscuramente, se mata en la carretera y el epílogo de su destino sólo merece de los amigos un comentario conformista y evasivo: "pobre, deciamos en el entierro, cuánto sufrió, qué vida tuvo, pero este final es un hecho que se lo buscó" (p. 102).

Casi todos los lectores y críticos de este relato han preferido leerlo, no como un episodio realista, sino como la trasposición simbólica de sus propios elementos anecdóticos. ¿Cuál es esa intrahistoria que quiere contarnos el autor en Los cachorros? ¿Se trata de una "parábola de la integración social" emancipada de toda obligación verista, como afirma Julio Ortega?" ¿Es su propósito denunciar que "la educación religiosa ha castrado a toda la generación a que alude Vargas Llosa?" (es decir, la suya propia), como cree Alfonso $\mathrm{La}$ Torre? ${ }^{5}$ ¿O, acaso, estamos ante "a parable of the fate an artist is exposed to in Hispanoamerica", como sugiere Luchting ${ }^{6}{ }^{6} \mathrm{O}$ es una ilustración psicoanalítica del complejo de castración? Aun cabría preguntar si este escorzo no nos está diciendo que toda etapa formativa del hombre es una castración, que la juventud (como ya lo apuntaba en su primera novela) no es una edad dorada sino una atroz marca de fuego que el adulto sobrelleva para siempre. La respuesta es muy ambigua porque el libro también lo es: el autor ha hecho de Los cacborros su narración más equívoca y perpleja. Sin duda la tesis de Luchting - la obra como un retrato del artista adolescentees la más audaz y tentadora, pero ella, como las otras, tiene el inconve-

4 La contemplación y la fiesta, Lima, Editorial Universitaria, 1968, p. 69.

s "Los cachorros o la castración generacional", Expreso, noviembre 5, 1967, p. 15 .

p. 277.

"Recent Peruvian Fiction", Researcb Studies, 35(4), diciembre 1967, 
niente de que limita el relato sólo a su nivel simbólico. Porque la obra opera también -y nuy eficazmente- a un nivel directamente realista. Y éste es un nivel que no sólo conviene tener presente, sino también examinar primero.

A la luz de sus libros anteriores, Los cachorros resulta una especie de vuelta de tuerca a la temática del machismo. Es como si ahora Vargas Llosa quisiera of recer el envés cómico del asunto, la mentira de su drama; por eso, Los cachorros parece un libro paródico, un brochazo burlesco en el retrato habitualmente trágico y ríspido del mundo adolescente. La historia de Pichula Cuéllar está contada como en sordina, mantenida en un nivel dramático deliberadamente más bajo del que podría haber alcanzado: la truculencia deriva en comicidad grotesca. Esto es una novedad casi absoluta en la obra de Vargas Llosa, una de cuyas más notables ausencias (la otra es la ausencia de Dios) es la del humor. "Yo siempre he sido absolutamente inmune al humor en literatura", ha declarado a Harss: "Hiela, congela. El humor es interesante cuando es una manifestación de rebelión: el humor insolente, corrosivo de un Céline. Puede ser una forma de amortiguar. Pero en general el humor es irreal. La realidad contradice el humor"." Y Sara Blackburn pudo afirmar que La Casa Verde era la obra de un autor "whose sense of humor has been eroded over the years -an aged Faulkner, say, but without the wit". ${ }^{8}$ Hemos dicho que el autor presenta la vida de Cuéllar como una historieta; pero esa calidad de su biografía se esparce a todo el relato y lo aproxima a las formas narrativas típicas del comic strip: la concentración del proceso narrativo en escenas de fácil reconocimiento, su dinamismo gráfico, la constante coordinación sonoro-visual, la reducción de un transcurso real bastante amplio en un tempo convencionalmente breve, etc. ${ }^{9}$ Ortega ha observado este mismo rasgo al indagar por el problema de verosimilitud en la obra: "Truculenta, irrisoria, la historia de Pichula Cuéllar se puede leer como un comic story tanto por el trazo rápido de sus escenas como por su también irrisorio y satírico uso de escenarios que son tópicos co-

7 Los nuestros, Buenos Aires, Sudamericana, 1966, p. 445.

8 "House affairs" (reseña de The Green House), The Nation, marzo 3 , 1969 , p. 280 .

- Cf. Umberto Eco, Apocalipticos e integrados ante la cultura de masas. Barcelona, Editorial Lumen, 1968, Cap. "El lenguaje del comia", pp. 69-76. Algunas observaciones de Eco sobre "El mito de Superman" (p. 257 y ss.) resultan aplicables, por antítesis a Cuéllar, a quien podría verse como encarnación del mito opuesto: el del hombre que ha perdido los poderes que le otorgaban superioridad. 
munes de la adolescencia. Esos escenarios típicos aquí sugieren la caricatura, el pastiche."10

Hay una deformante exageración en todo (que a Ortega le induce a creer que también la castración es "poco posible"), una voluntad de aniquilar los ídolos de la niñez y la juventud mostrándolos en sus tintas más cargadas. Cuando los "cachorros" hablan de tomar venganza del perro Judas (nombre en sí mismo muy farsesco), Cuéllar divaga y echa mano de los símbolos fantasiosos de los comics y los mezcla con la realidad: "cuando saliera iríamos al Colegio de noche, y entraríamos por los techos, viva el jovencito pam pam, el Aguila Enmascarada chas chas, y le hariamos ver estrellas, de buen humor pero flaquito y pálido, a ese perro, como él a mí" (p. 25). Las bromas y tomaduras de pelo colegiales se incorporan también como parodias de la vida de relación: "quiero ser tu amigo y le mandaba un beso y te adoro, ella sería la vaca y yo seré el toro, ja ja" (p. 41); "qué ocurrencia, qué tenían, qué nos pasaba (Pusy: la saliva por la boca y la sangre por las venas, ja ja" (p. 86). Pero es, sobre todo, el uso intensísimo de las onomatopeyas y grafismos lo que recuerda el lenguaje clásico del comic strip, es decir, la imagen visual y el sonido convencional (el "globito") unido a ella; estos son algunos ejemplos:

...y Cuéllar sacaba su puñalito y chas chas lo sonaba, deslonjaba y enterrabaaaaaauuuu, mirando al cielo, uuuuuuaaauuu, las dos manos en la boca, auauauauauauuuu: ¿qué tal gritaba Tarzán? (pp. 18-19).

... absortos en los helados, un semáforo, shhp chupando shhhp y saltando hasta el edificio San Nicolás... (p. 19).

...y él vsssst por el Malecón vsssst desde Benavides hasta la Quebrada vsssst en dos minutos cincuenta, ¿lo batí?" (pp. 51-52).

...y, de pronto, Pichulita, sssí le gggggustabbbban, comenzaba, las chicccas decenttttes, a tartamudear, sssólo qqqque la flaccca Gamio nnno, ellas ya te muñequeaste y él addddemás no habbbía tiempo por los exámmmenes y ellos déjenlo en paz... (p. 56).

...quisiera tener un revólver, ¿para qué, hermanito?, con diablos azules, ¿para matarnos?, sí y lo mismo a ese que pasa pam pam y a ti y a mí también pam pam; un domingo invadió la Pelouse del Hipódromo y con su Ford ffffuum embestía a la gente ffffuum 
que chillaba y saltaba las barreras, aterrada, fffuum. En los Carnavales, las chicas le huían: las bombardeaba con proyectiles hediondos, cascarones, frutas podridas, globos inflados con pipi y las refregaba con barro, tinta, harina, jabón (de lavar ollas) y betún: salvaje, le decían, cochino, bruto, animal, y se aparecía en las fiestas del Terrazas, en el Infantil del Parque de Barranco, en el baile del Lawn Temnis, sin disfraz, un chisquete de éter en cada mano, píquiti piquiti juas, le di, le di en los ojos, ja jai, píquiti píquiti juas, la dejé ciega, ja ja, o armado con un bastón para enredarlo en los pies de las parejas y echarlas al suelo: bandangán (pp. 64-65).

Este realismo cómico quiere mostrar los extremos absurdos y jocosos a los que el culto del machismo puede llegar: Los cacborros es un libro antiheroico. Pero lo anterior deja en pie la pregunta sobre el significado que esta visión puede tener, sobre sus indudables aristas simbólicas. Desde este ángulo, la obra es una metáfora social de inquietante poder alusivo, y dice más de lo que parece. Cuéllar es la encarnación del individuo incapacitado para la vida en sociedad. Para estos efectos, importa relativamente poco que su castración sea física o imaginaria (la idea de la castración como impuesta por los demás). Cuéllar pertenece a esa raza de: seres intimidados a la que pertenece el Esclavo; pero es menos honrado consigo mismo que éste (quien, hasta el fin, es la víctima natural de toda la violencia leonciopradina), porque adopta los moldes comunes que le dictan los otros y realiza un doble juego para sobrevivir entre ellos como un igual. La actitud del grupo hacia él pasa de la simpatía inicial al franco repudio, pero aún esa simpatía está condicionada al cum. plimiento de las leyes colectivas. Desde el comienzo, la idea del compañerismo infantil ya está viciada:

Y, además, buen compañero. Nos soplaba en los exámenes y en los recreos nos convidaba chupetes, ricacho, tofis, suertudo, le decía Choto, te dan más propina que a nosotros cuatro, y él por las buenas notas que se sacaba, y nosotros menos mal que eres buena gente, chanconcito, eso lo salvaba (p. 14).

Ser estudioso no le basta a Cuéllar: tiene que demostrar también que es buen deportista para mantener el aprecio dentro de su pequeña sociedad:

Buena gente pero muy chancón, decía Choto, por los estudios descuida el deporte, y Lalo no era culpa suya, su viejo debía ser un 
fregado, y Chingolo claro, él se moría por venir con ellos y Mañuco iba a estar bien difícil que entrara al equipo, no tenia físico, ni patada, ni resistencia, se cansaba ahí mismo, ni nada. Pero cabecea bien, decía Choto, y además era hincha nuestro, habia que meterlo como sea decía Lalo, y Chingolo para que esté con nosotros y Mañuco sí, lo meteríamos, jaunque iba a estar más difícil! (pp. 19-20).

Hasta podría llegar a entenderse el accidente de Cuéllar como una especie de sanción indirecta que se le infiere por su incompleta adaptación al grupo; al comienzo del relato, Mañuco dice una frase respecto del perro Judas que tiene un ambiguo sentido premonitorio dentro del contexto: "los daneses sólo mordían cuando olían que les tienes miedo" (p. 14). Ergo, Cuéllar es castrado porque tenía miedo y su castigo guarda una secreta proporción con su culpa. Progresivamente, la vida de Cuéllar se va haciendo más falsa, más irreal; en su persecución desesperada de los ideales del machismo, se niega a aceptar la verdadera adultez: esa alienación lo conducirá a la muerte.

Pero el aspecto simbólico más importante de Los cachorros es que la alienación de Cuéllar es como el reflejo inverso de otra, más sutil, que se apodera de los amigos que lo condenaron. En el capítulo IV del libro hay una escena clave: por un momento, antes de emborracharse completamente, Cuéllar tiene el conmovedor coraje de confesar que ama a Teresa y que la quiere para siempre, mientras los demás hablan de las chicas como un simple medio para probar su virilidad; por un momento, Cuéllar parece más sincero (y menos enajenado por los mandamientos del código juvenil) que los otros:

Le caería, tendría enamorada y él ¿qué haria? y Choto tiraría plan y Mañuco le agarraría la mano y Chingolo la besaría y Lalo la paletearía su poquito y él ¿y después? y se le iba la voz y ellos ¿después?, y él después, cuando crecieran y tú te casaras, y él y tú y Lalo: qué absurdo, cómo ibas a pensar en eso desde ahora, y además es lo de menos. Un día la largaría, le buscaría pleito con cualquier pretexto y pelearía y así todo se arreglaría y él, queriendo y no queriendo hablar: justamente era eso lo que no queria, porque, porque la quería. Pero un ratito después - diez Cristales ya- hermanos, teníamos razón, era lo mejor: le caeré, estaré un tiempo con ella y la largaré (p. 82). ${ }^{11}$

11 La actitud de Alberto, en La ciudad y los perros, es básicamente la misma (p. 335$)$. 
Al final, la regresión al infantilismo de Cuéllar se dibuja contra un fondo de general aburguesamiento: cuando queda atrás la mitología que unía a los "cachorros", sus destinos se aflojan, se hunden en la mediocridad, repiten pacíficamente el negado ciclo de sus padres. A la derrota notoria de Cuéllar, inadaptado para siempre con su mundo, corresponde otra derrota, más lenta y corrosiva, de los que se someten hipócritamente a una sociedad alienada por los falsos valores de la figuración y el dinero. El párrafo que cierra la narración, espléndido en su penetrante ironía, ${ }^{12}$ resume esa renuncia a la vida auténtica, esa domesticación de los antiguos rebeldes:

Eran hombres hechos y derechos ya y teníamos todos mujer, carro, hijos que estudiaban en el Champagnat, la Inmaculada o el Santa María, y se estaban construyendo una casita para el verano en Ancón, Santa María o las playas del Sur, y comenzábamos a engordar y a tener canas, barriguitas, cuerpos blandos, a usar anteojos para leer, a sentir malestares después de comer y de beber y aparecian ya en sus pieles algunas pequitas, ciertas arruguitas (p. 105).

Otra vez, Vargas Llosa se niega a dividir a los hombres en buenos y malos. Es como si quisiera decirnos que nuestras sociedades burguesas (con su fariseísmo, con sus anquilosados moldes de vida) son siempre agresivas para el individuo que se rebela o dañinas para el sujeto que se adapta. Sea Cuéllar la imagen de la castración espiritual de la clase media producida por un sistema educativo-religioso (tesis de La Torre), sea el símbolo del artista incomprendido y ridiculizado por la sociedad (tesis de Luchting), lo cierto es que su historia y la de sus amigos muestran las consecuencias atroces que el espíritu burgués, tal como lo experimentan los jóvenes, acarrea a una colectividad como la peruana.

La originalidad mayor del libro no está, sin embargo, en su realismo cómico ni en su simbolismo social, sino en la invención de una forma que constituye uno de los experimentos narrativos más audaces que se hayan intentado en español. Los cachorros es un fragmento de una exploración total cuyos alcances todavía no han sido agotados por el autor: es un campo experimental, un "capítulo de ensayo"13 del que cabe esperar futuros desarrollos. El punto de partida está, como dijimos, en La Casa Verde, concretamente en sus procedimientos narrativos pluridimensiona-

12 Martinez Moreno (loc. cit., p. 86) cree, al contrario, que es un párrafo innecesario.

13 Carlos Barral, op. cit., p. 9. 
les: Pero el novelista se planteó su trabajo en términos nuevos: " . . sigo luchando con un cuento que está construido (escribe en una carta, mientras redactaba Los cachomos) integramente sobre este procedimiento, que consiste en expresar simultáneamente la realidad objetiva y la subjetiva en una misma frase, mediante combinaciones rítmicas" ${ }^{14}$ Lo consigue haciendo que distintos tiempos y personas verbales sirvan al mismo sujeto psicológico, visto simultáneamente como un ellos y como un nosotros en su formulación gramatical. ${ }^{15}$ El primer párrafo del relato nos instala de inmediato en un mundo narrativo envolvente y coral:

Todavia llevaban pantalón corto ese año, aún no fumábamos, entre todos los deportes preferían el fútbol y estábamos aprendiendo a correr olas, a zambullirnos desde el segundo trampolín del Tern$z a s$, y eran traviesos, lampiños, curiosos, muy ágiles, voraces (p. 13).

Lugares, acciones, diálogos, pensamientos, ruidos, fantasías, observaciones indeterminadas, frases sueltas, etc., todo es arrastrado bajo el empuje de esta prosa espasmódica, galvanizadora, casi líquida, que serpentea y late como un pulso, devorando el espacio y el tiempo. En ese torrente, la ansiada objetividad de Vargas Llosa queda nuevamente a salvo: escribe y dice con la voz de sus protagonistas; es, como dice Alfredo Matilla Rivas, "uno de los personajes y ninguno, y todos; ... a la vez el narrador omnisciente y el que sólo puede referirse a la experiencia vivida". ${ }^{16}$ Llevado por ese ímpetu, el autor ignora audazmente (para desesperación de sus traductores) las últimas vallas del idioma y, en los vívidos movimientos de ese organismo verbal, cambia de ritmo, suprime verbos, tuerce el sentido del discurso narrativo y confunde las personas de la acción:

los seleccionados nos vestíamos para a sus casas a almorzar (p. 23). ellos lo estábamos vengando (p. 25)

aunque se secreteaban él, desde mi cama de la clínica, los oyó (p. 31) se los había metido al bolsillo a mis papás (p. 32)

14 Carta de enero 22, 1966. cit. por Luchting, "Recent Peruvian Fiction", loc. cit., p. 277.

${ }_{15}$ Cf. la interesante referencia que hace Martínez Moreno (loc. cit., p. 85) a un semejante planteo formal, aunque sólo "a título de posibilidad cuasi fantástica", en el comienzo del cuento "Las babas del diablo", de Cortázar Se. puede rastraer más atrás y hallar una insinuación del procedimiento en "Lejana" (de Bestianio): "Porque a mi, a la lejana, no la quieren..."

16 Reseña de Los cacborros, Asomante, núm. 3, 1968, p. 99: 
al principio ellos le poníamos mala cara (p. 81)

entonces volvíamos a nuestras casas y se duchaban y acicalábamos y Cuéllar los recogía en el poderoso Nash (p. 91).

Como en ocasiones anteriores, las analogías más próximas son de orden visual: el efecto estilístico de este procedimiento puede asimilarse a. de una cámara cuyo obturador se abriese y cerrase continuamente (Benedetti habla de un "switch"), variando cada vez los objetos, el foco, los ángulos, el sujeto; o, directamente, a las imágenes cinematográficas discontinuas y súbitas de Godard o Resnais. El esfuerzo de Vargas Llosa está dirigido a intentar la narración en todas las personas a la vez hasta disolver los puntos de vista individuales en una sola entidad dramática, en una especie de narrador colectivo que relata en un continuum avasallador. Pero si los personajes se unifican en un gran Nosotros, ese Nosotros quisiera abrazar también al lector y hacerlo copartícipe. Benedetti afirma que es "una manera de instalar a su lector en esa culpa tribal, de hacerle sentir de alguna manera un escozor de prójimo". ${ }^{17}$

La intimidad (o complicidad) con el lector está asegurada también por el uso copioso de expresiones de la jerga colegial y por la insinuante captación de los timbres orales (un poco cariñosos, un poco pícaros) de1 lenguaje oral limeño. La jerga y los usos locales no son una novedad para los que han frecuentado las novelas de Vargas Llosa, pero su frecuencia es aquí mucho más alta que en cualquiera de sus obras, y hasta puede temerse que los menos familiarizados con esos giros perderán muchos matices importantes de la historia: ${ }^{18}$ la anécdota es, indisolublemente y más que nunca, el lenguaje que la expresa. En cuanto a la presencia masiva de los diminutivos (las escenas en que Teresita habla con Cuéllar y con el grupo, p. 74-80, son una exaltación de esta forma encarecedora), crea el tono indulgente y dulzón, íntimo y cordial del texto, y (como Julio Ortega ha señalado) transparenta el infantilismo y la complacencia en la que se van hundiendo los personajes por rechazo o absorción de la sociedad. ${ }^{19}$

17 Op. cit., p. 200.

18 Bastan algunos ejemplos: siriaba por 'enamoraba', buitreándose por 'vomitándose', perro muerto por 'estafa', tocan' violin por 'quedar al margen', andaba muca por 'andaba sin dinero', etc.

$19 O p$. cit., p. 68 . La alienación es también lingüística y los muchachos repiten mecánicamente las fórmulas verbales que difunden la radio y la jerga deportiva: de Cuéllar dicen que es "un poco loquibambio" (p. 14); sus "virtudes futbolísticas merecen estos comentarios: "Cómo has hecho? decía Lalo, ¿de dónde esa cintura, esos pases, esa codicia de pelota, esos trros al ángulo?... Sí, ha mejorado mucho, le decía Choto al Hermano Lucio, el entrenador, de- 
Los cachorros confirma, aun en su brevedad, la destreza del autor para apresar ambientes, conflictos e individualidades que le permiten retratar las contradicciones de la sociedad peruana, y su infatigable voluntad de crearse los instrumentos expresivos que las encarnen en visiones totales, en mitos, en metáforas de validez autónoma. Hasta aquí la tarea creadora de Vargas Llosa ha mostrado claramente cuál es su objetivo: la tenaz invención artística de una realidad.

Universidad Católica, Lima, Perú.

José Miguel Oviedo

veras, y Làlo es un delantero ágil y trabajador, y Chingolo qué bien arganizaba el ataque $\mathrm{y}$, sobre todo, no perdía la moral, y Mañuco ¿vio cómo baja basta el arco a buscar pelota cuando el enemigo va dominando? (p. 20). 